to damage by cytotoxic drugs. A study of childhood-cancer survivors, however, showed no evidence of a raised rate of spontaneous abortions or malformations in the progeny of men after treatment with various cytotoxic agents. ${ }^{1}$ On the other hand, a recent report has described two cases of severe malformations after chemotherapy for acute myelogenous leukaemia in two men. ${ }^{2}$

In our case the lack of malformations in the child born after the second pregnancy is noteworthy as the father had been treated with MTX and 6-MP at the time of conception for over one and a half years. Both drugs are known to carry a definite teratogenic risk in the mother. ${ }^{2}$ In view of the considerable rate of spontaneous abortions in the general population, it is not possible to decide whether the previous abortion was due to a mutagenic effect of the chemotherapy, was otherwise related to the malignancy, or was purely coincidental.

The improvements in chemotherapy have led to increasing numbers of young long-time survivors of malignant disease. These patients often seek information about the risk to the fetus in case of a pregnancy. To obtain data for better counselling more reports about the outcome of such pregnancies are needed. Roten Kreuz, Zürich, for testing the affiliation and Prof W Schmid, Universitäts-Kinderklinik, Zürich, for the chromosomal analysis.

$1 \mathrm{Li}, \mathrm{F} \mathrm{P}$, and Jaffe, N, Lancet, 1974, 2, 707

2 Schein, P S, and Winokur, S H, Annals of Internal Medicine, 1975, 82, 84.

${ }^{3}$ Russell, J A, Powles, R L, and Oliver, R T D, British Medical fournal, $1976,1,1508$.

(Accepted 7 February 1977)

Medizinische Poliklinik, Kantonsspital, Winterthur, Switzerland TH KRONER, MD, registrar

Kinderklinik, Kantonsspital, Winterthur, Switzerland
We thank Dr M Metaxas, Blutspendezentrum des Schweizerischen A TSCHUMI, MD, registrar

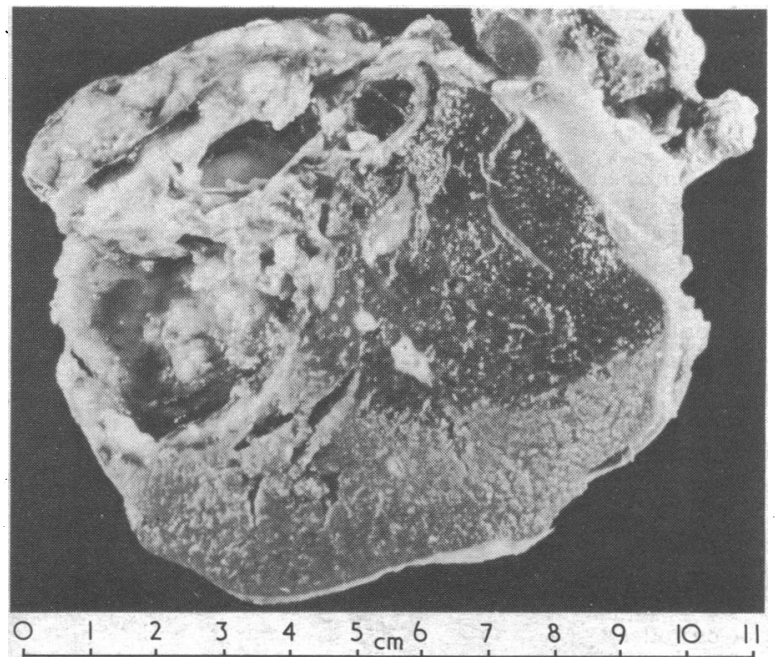

Specimen obtained at splenectomy showing an abscess in the upper lobe of the spleen.

osteomyelitis, mycotic aneurysms, meningitis, postgastrectomy enteritis, pneumonitis, and salmonella "appendicitis." The organisms most frequently implicated in these cases have been $S$ typhimurium and $S$ chloeraesuis. We believe that the development of an empyema due to a typhoid splenic abscess in a previously healthy patient is an extremely unusual complication of the disease. The present-day rarity of typhoid splenic abscess itself is confirmed by a recent review, ${ }^{5}$ which states that no case has been reported since 1940 .

1 Carrera Boadella, A, Rubies Prat, J, and Foz Sala, M, Medica Clinica, 1968, 51, 528.

2 Ransohoff, J L, and O'Rourke, W, fournal of the American Medical Association, 1940, 114, 2543.

Saphra, I, and Winter, J, New England fournal of Medicine, 1957, 256, 1128.

- Black, P H, Kunz, L J, and Swartz, M N, New England fournal of Medicine, $1960,262,811,864,921$.

Chulay, et al, American fournal of Medicine, 1976, 61, 513.

(Accepted 1 February 1977)

\section{Empyema due to splenic abscess in typhoid fever}

Typhoid fever is one of the commonest infectious diseases seen at our hospital, where naturally we encounter many of the classical complications. We report here a patient with typhoid fever who developed a rare complication: splenic abscess and empyema due to Salmonella typhi.

\section{Case report}

A 13-year-old girl was admitted to our hospital with two weeks' history of fever. Examination showed that she had a soft, slightly enlarged spleen. Investigations disclosed: haemoglobin $11 \mathrm{~g} / \mathrm{dl}$; white cell count $6.1 \times$ $10^{\circ} / 1$, with no eosinophils; ESR $40 \mathrm{~mm} 1$ hour; chest $x$-ray film was normal.

The result of blood culture was negative. Agglutinins against the somatic (0) and flagellar antigens of $S$ typhi were $1 / 80$ and $1 / 640$, respectively. Typhoid fever was diagnosed and she was started on chloramphenicol, $2 \mathrm{~g}$ daily. The girl was discharged on the tenth day symptom-free, but four days later fever returned and she complained of left pleuritic pain. The chest $x$-ray film showed appearances consistent with a left pleural effusion, and this was confirmed on thoracocentesis: the fluid was purulent and on culture grew $S$ typhi. A splenic scintiscan disclosed a defect in the upper lobe of the spleen. Findings in an arteriogram was compatible with an abscess. After several pleural taps and further antibiotic treatment $(24 \mathrm{~g}$ of chloramphenicol) she underwent splenectomy and the diagnosis of splenic abscess was confirmed. No organisms were grown from the pus from the abscess on culture. Her postoperative course was uneventful.

\section{Discussion}

A rare complication of typhoid is suppurative cysts of the ovary, ${ }^{1}$ while abscesses of the spleen have been reported in patients with haemolytic disorders. ${ }^{2}$ Other infective foci ${ }^{34}$ of salmonellosis include

\section{Aide-mémoire for preparing clinical trial protocols}

The list below may serve as an aide-mémoire for those planning clinical trials. It assumes some basic knowledge of clinical trial methodology, but a few of the headings are amplified in footnotes. Further information is available in textbooks such as Principles and Practice

\section{Aide-mémoire}

1.0 Description and rationale

1.1 Short title

1.2 Descriptive title

1.3 Trial number (serial number and date of revision; insert "draft" until finalised)

1.4 Contact and phone number

1.5 Aim of trial: questions to be answered

1.6 Reasons for doing it of Clinical Trials. 